\title{
In vitro and in vivo efficacy of 6-(7-nitro-2,1,3-benzoxadiazol- 4-ylthio)hexanol (NBDHEX) on human melanoma
}

\author{
Francesca Pellizzari Tregno ${ }^{a}$, Andrea Sau $^{a}$, Silvia Pezzola ${ }^{a}$, Cristina Geroni ${ }^{b}$, \\ Caterina Lapenta ${ }^{c}$, Massimo Spada $^{c}$, Giuseppe Filomeni ${ }^{d}$, Elena Bonanno ${ }^{e}$, Giorgio Federicif, \\ Anna Maria Caccuri ${ }^{a, *}$ \\ aDepartment of Chemical Sciences and Technologies, University of "Tor Vergata", Rome, Italy \\ ${ }^{\mathrm{b}}$ Nerviano Medical Sciences, Oncology, Nerviano, Italy \\ ${ }^{\mathrm{c} D e p a r t m e n t}$ of Cell Biology and Neurosciences, Section of Experimental Immunotherapy, Istituto Superiore di Sanità, Rome, Italy \\ dDepartment of Biology, University of "Tor Vergata", Rome, Italy \\ eDepartment of Biopathology, Section of Anatomopathology, University of "Tor Vergata", Rome, Italy \\ ${ }^{\mathrm{f}}$ Children's Hospital IRCCS "Bambin Gesu"” Rome, Italy
}

\section{A R T I C L E I N F O}

Article history:

Received 5 May 2009

Received in revised form 18 June

2009

Accepted 25 June 2009

Available online 6 August 2009

Keywords:

NBDHEX (6-(7-nitro-2,1,3-

benzoxadiazol-4-ylthio)hexanol)

Melanoma

JNK (c-Jun N-Terminal Kinase)

GSTP1-1 (Glutathione S-transferase

Pi)

Antitumour drug

\begin{abstract}
A B S T R A C T
6-(7-Nitro-2,1,3-benzoxadiazol-4-ylthio)hexanol (NBDHEX) is a powerful inhibitor of the glutathione transferase P1-1 (GSTP1-1) and causes the disruption of the complex between GSTP1-1 and c-Jun N-terminal Kinase (JNK). This induces JNK activation and apoptosis in tumour cells. In the present work we assess the in vitro and in vivo effectiveness of NBDHEX on two human melanoma cell lines, Me501 and A375. NBDHEX shows $\mathrm{IC}_{50}$ values in the low micromolar range ( $\mathrm{IC}_{50}$ of $1.2 \pm 0.1 \mu \mathrm{M}$ and $2.0 \pm 0.2 \mu \mathrm{M}$ for Me501 and A375, respectively) and is over 100 times more cytotoxic to these cell lines than temozolomide. Apoptosis is observed in Me501 cells within $3 \mathrm{~h}$ of the addition of NBDHEX, while in A375 cells the apoptotic event is rather late, and is preceded by a G2/M phase arrest. In both melanoma cell lines, JNK activity is required for the ability of NBDHEX to trigger apoptosis, confirming that the JNK pathway is an important therapeutic target for this tumour. NBDHEX is also both effective and well tolerated in in vivo tumour models. A tumour inhibition of $70 \%$ is observed in vivo against Me501 human melanoma and a similar result is obtained on A375 model, with $63 \%$ of tumour inhibition. These findings indicate that the activation of the JNK pathway, through a selective GSTP1-1 targeting, could prove to be a promising new strategy for treating melanoma, which responds poorly to conventional therapies.
\end{abstract}

(c) 2009 Elsevier Ltd. All rights reserved.

\section{Introduction}

The increased incidence of human melanoma ${ }^{1}$ poses an enormous challenge due to its high aggressiveness and lethality, with the major problem being its pronounced resistance to therapy. ${ }^{2}$ Therapies that include dacarbazine, an alkylating agent, are still the most commonly utilised ones for metastatic melanoma; in fact, several dacarbazine combination studies have been performed in recent years, using other antitumour drugs and/or biological therapy drugs such as interferon or interleukin, yet none of these such drugs significantly improve the survival rate or even the response rate. ${ }^{3,4}$ Temozolomide is a novel alkylating agent that has demonstrated antitumour activity comparable to that of the current standard treatment, dacarbazine, with the additional benefit of being able to penetrate the blood-brain barrier. ${ }^{5}$ Nevertheless, the enhancement

\footnotetext{
* Corresponding author: Tel.: +39 672596204 .

E-mail addresses: caccuri@uniroma2.it, nbdhex@yahoo.it (A.M. Caccuri). 0959-8049/\$ - see front matter @ 2009 Elsevier Ltd. All rights reserved. doi:10.1016/j.ejca.2009.06.033
} 
of long-lasting response and survival is still extremely limited and surgical removal of the tumour remains the only curative treatment of malignant melanoma. Since cancer therapies aim at the elimination of tumour cells through apoptotic cell death, there are strong reasons to believe that the ineffectiveness of chemotherapy in treating melanoma is mainly due to the improper functioning of said apoptosis programmes. Therefore, an essential therapeutic target for melanoma treatment is the development of novel drugs that, either alone or in combination, induce apoptosis and suppress survival pathways. ${ }^{6}$ For this reason we decided to evaluate the activity of NBDHEX in human melanoma cell lines. This molecule is a promising anticancer drug which activates the JNK pathway through the targeting of the GSTP1-1 enzyme. 7 GSTP1-1 is involved in cellular resistance to anticancer drugs ${ }^{8}$ and binds to NBDHEX with high affinity, inducing the dissociation of the GSTP1-1-JNK complex and triggering a remarkable apoptotic effect in a variety of human cancer cell lines. The GSTP1-1 enzyme can cooperate with the multiple drug resistance protein (MRP1) and the non-ABC multi-specific transporter RLIP76/RALBP1 to protect melanoma cells from the toxic effects of chemotherapies. ${ }^{9,10}$ Moreover, the export pump P-glycoprotein (P-gp) may also be overexpressed in melanoma, this being associated with an increased invasive behaviour of the tumour. ${ }^{11}$ It is well known that NBDHEX is not a substrate of MRP1 or P-gp export pumps ${ }^{12-14}$ and its possible interaction with RLIP76 is under investigation. In this study we show that NBDHEX is able to trigger apoptosis in the Me501 melanoma cell line through the activation of the JNK/C-Jun pathway. We also tested this compound on A375 melanoma cells, which are known to express high levels of GSTP1-1 and MRP1. ${ }^{9}$ In addition, this cell line over expresses Bcl-2, FLIP and IAPs (XIAP and survivin), which all contribute to the prevention of caspase activation and apoptosis. ${ }^{15}$ We found that NBDHEX also causes cell death in the A375 cell line, even though the time course of apoptosis is different. Moreover, NBDHEX induces a significant growth inhibition of both tumours in melanoma mouse models, highlighting the in vivo antitumour efficacy of this molecule for the first time.

\section{Materials and methods}

\subsection{Drugs}

NBDHEX was synthesised as reported by Ricci and colleagues $^{16}$ and dissolved in DMSO. SP600125 and SB203580 were purchased from Calbiochem-Novabiochem (Darmstadt, Germany). Cycloheximide and Temozolomide were Sigma Co. (St. Louis, MO) products.

\subsection{Cell lines, culture and treatments}

The Me501 cell line was generated from tissue obtained from a metastatic melanoma patient, ${ }^{17}$ while the human melanoma cell line A375 was obtained from the American Type Cell Culture Collection (ATCC). Cells were maintained at $37^{\circ} \mathrm{C}$ and $5 \%$ $\mathrm{CO}_{2}$ in a humidified atmosphere in RPMI (Me501) or DMEM (A375), supplemented with $10 \%$ FBS (v/v), $2 \mathrm{mM}$ L-glutamine, $100 \mathrm{U} / \mathrm{mL}$ of penicillin and $100 \mathrm{mg} / \mathrm{mL}$ streptomycin (Sigma Co., St. Louis, MO). For all the experiments, cells were seeded in culture flasks at a density of 50,000 cells $/ \mathrm{cm} .^{2}$ After $48 \mathrm{~h}$, the cells were exposed to NBDHEX and allowed to incubate for up to $48 \mathrm{~h}$. NBDHEX was diluted in culture medium at the desired concentration immediately before use. The DMSO concentration in the culture medium never exceeded $0.01 \%$ (v/v), a dosage at which it has no cytotoxic effect on our cell lines. NBDHEX was also added to cells that were pre-treated for $1 \mathrm{~h}$ with the JNK inhibitor SP600125 $(20 \mu \mathrm{M})$, for $30 \mathrm{~min}$ with the p38 inhibitor SB203580 $(10 \mu \mathrm{M})$ or for $1 \mathrm{~h}$ with the protein synthesis inhibitor cycloheximide $(36 \mu \mathrm{M})$. Cells were collected at different time points and frozen for further analysis.

\subsection{Cell growth assay}

Drug (either NBDHEX or Temozolomide) cytotoxicity was determined in Me501 and A375 cell lines by the sulphorhodamine $B$ assay ${ }^{18}$ (SRB, Sigma). In brief, the cells $\left(2 \times 10^{4}\right.$ cells per well) were exposed to the drug at the required concentrations and allowed to incubate for $48 \mathrm{~h}$. After incubation, the cell growth was evaluated by an in situ cell-fixation procedure followed by a specific colour reaction of proteins with SRB. The dose-response profile obtained fulfils the drug concentration needed to obtain $50 \%$ of cellular growth inhibition (IC $\mathrm{I0}_{50}$ ).

\subsection{Apoptosis, necrosis and cell-cycle assay}

All cell treatments were performed by using an NBDHEX concentration five times the $\mathrm{IC}_{50}$ values found in these cell lines; i.e. Me501 and A375 cells were incubated with $5 \mu \mathrm{M}$ and $10 \mu \mathrm{M}$ NBDHEX, respectively. For necrosis determination, aliquots of cells were stained with trypan blue and examined by microscopy. Apoptosis was determined with fluorescence microscopy by estimating the number of nuclei with typical apoptotic morphology after DNA staining with the dye Hoechst 33342 (Sigma). Apoptosis was also confirmed by measuring caspase- 3 activity through the use of the model fluorescent peptide N-AcetylAsp-Glu-Val-Asp-7-amido-4-trifluoromethylcoumarin (AcDEVD-AFC, Sigma) as reported by Turella et al. ${ }^{7}$ Caspase activity was calculated as fluorescence change, measured within $1 \mathrm{~min}$ from the substrate addition, and normalised per cell. For cellcycle analysis, cells were fixed with $70 \%$ ethanol (v/v), stained with propidium iodide and analysed by a FACSCalibur instrument (Becton-Dickinson, San Jose, CA, USA).

\subsection{Western blot assay}

Cell pellets were treated as previously reported. ${ }^{7}$ Proteins $(30 \mu \mathrm{g})$ were loaded into a $12 \%$ SDS-polyacrylamide gel and transferred onto a nitrocellulose membrane (Bio-Rad). Monoclonal antiphospho-activated JNK isoform (1:1000, Santa Cruz), polyclonal antiphospho-activated c-Jun (1:1000, Cell Signaling), monoclonal antip21 ${ }^{\text {Waf1/Cip1 }}$ (1:2000, Cell Signaling), anticaspase-8 (1:1000, Upstate) and -9 (1:1000, Cell Signaling) and anti $\beta$-tubulin (1:5000, Sigma) were used as primary antibodies. Antirabbit and antimouse secondary antibodies (Sigma) were used at the appropriate dilutions.

\subsection{In vivo tumour xenograft study}

The in vivo antitumour efficacy of NBDHEX was evaluated on human melanoma (Me501 and A375) models. Tumour cells 
were injected subcutaneous (s.c.) into the right flank of immunodeficient mice $\left(2 \times 10^{6}\right.$ cells/mouse). The animals were then divided into groups of eight and used at 4-5 weeks of age to avoid immunoglobulin production and B-lymphocyte generation (leaky phenotype). Me501 cells were easily transplanted into SCID mice which are even more immunodeficient than nude mice and represent a good model for the investigation of the in vivo behaviour of the Me501cell line. When the tumour was about $20 \mathrm{~mm}^{3}$, CB.17 SCID/SCID female mice (Harlan, Italy) were treated (daily $\times 20$ ) with $0.8,8.0$ or $80 \mathrm{mg} / \mathrm{kg} / \mathrm{d}$ of NBDHEX administered per os in a volume of $0.2 \mathrm{ml}$ of DMSO. A375 xenografts were established in athymic (nude) mice which are the standard recipients of this human malignancy. As soon as the tumours reached an average volume of $100-200 \mathrm{~mm}^{3}$, athymic Balb Nu/Nu male mice (Harlan, Italy) were treated (daily $\times 10$ ) with 40 or $75 \mathrm{mg} / \mathrm{kg} / \mathrm{d}$ of NBDHEX. The drug was prepared in a vehicle of $0.5 \%$ Methocel $(\mathrm{w} / \mathrm{v})$ and administered per os in a volume of $0.2 \mathrm{ml}$. All NBDHEX solutions were prepared immediately before use. Tumour growth inhibition (TI) was monitored three times a week. Tumour growth was evaluated by measuring maximal and minimal diameters by caliper, and tumour weight was estimated according to the following formula: tumour weight $(\mathrm{mg})=d^{2} \times \mathrm{D} / 2$ (where $d$ is the minor diameter $(\mathrm{mm})$ and $D$ is the major diameter $(\mathrm{mm})$ ). At sacrifice, tumours were excised, fixed in a $10 \%$ buffered formalin (v/v), paraffin embedded and then cut into $5 \mu \mathrm{m}$-thick slices for staining. A set of slides was stained with haematoxylin eosin for the morphological study and the count of mitosis. Additional slides were stained with antibodies against Ki-67, cyclin D1 and caspase-3. Reactions were revealed with 3,3'-diaminobenzidine (DAB). All internal organs were fixed and paraffin embedded for the morphological study to evaluate drug effects in normal tissues. Toxicity was evaluated on the basis of weight loss and morphological analysis of internal organs. Treatments and experimental handling of animals were done according to the EU Directive (86/609) and Italian law (D.Lvo 116/1992). A veterinary surgeon was present to check the health status of the animals to avoid physical injury, suffering and distress.

\subsection{Statistical analysis}

All the experiments were repeated at least three times; results are presented as means \pm SD. Statistical evaluation was done using the Student's t-test. The criterion for statistical significance used was $P<0.05$.

\section{Results}

3.1. Cytotoxic effect of NBDHEX on Me501 and A375 cell lines

We first measured the NBDHEX uptake and efflux kinetics in both A375 and Me501 cell lines as previously reported ${ }^{12}$. Flow
A

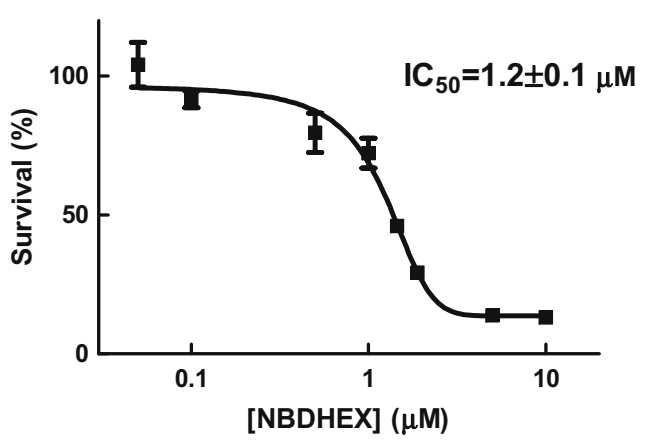

B

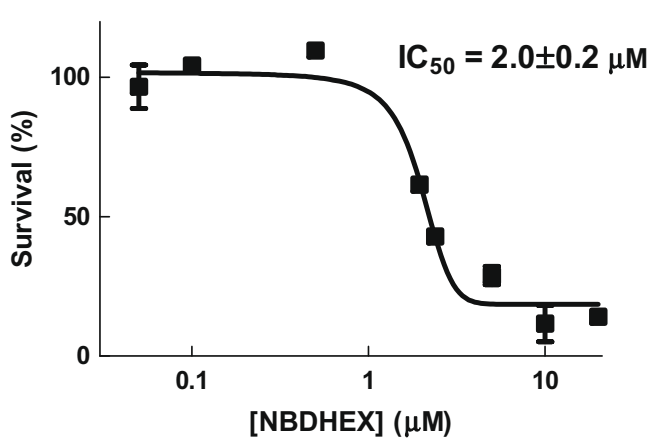

C Me501

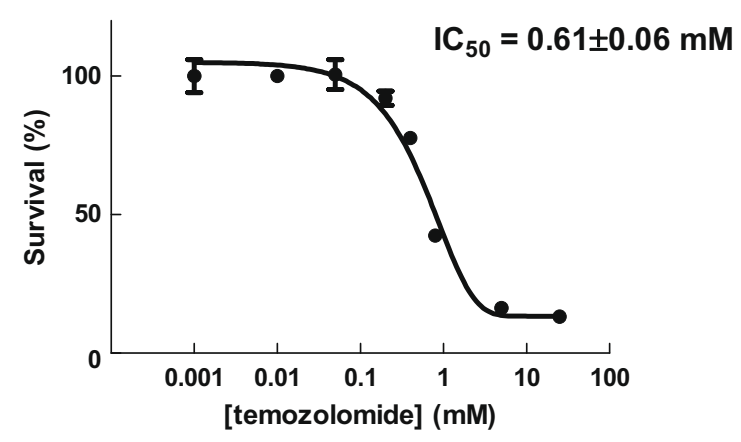

D $\quad$ A375

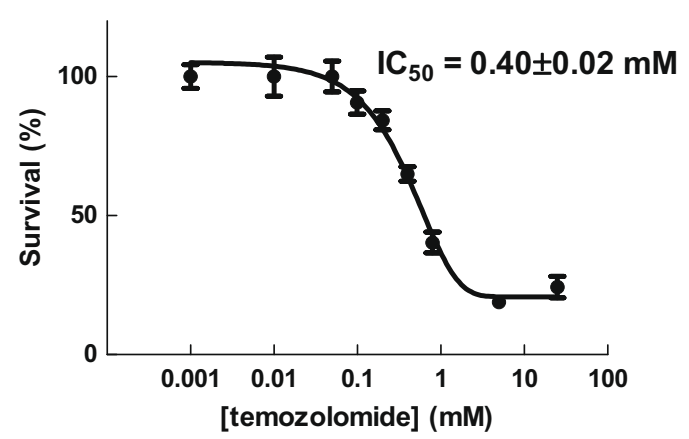

Fig. 1 - Cytotoxic activity of NBDHEX on melanoma cell lines. Human melanoma Me501 (Panel A) and A375 (Panel B) cell lines were incubated with different NBDHEX concentrations (from 0.05 to $20 \mu \mathrm{M}$ ). After $48 \mathrm{~h}$ of treatment, cell growth was evaluated by the SRB assay (see Section 2). The dose-response profile obtained gave $\mathrm{IC}_{50}$ values of $1.2 \pm 0.1 \mu \mathrm{M}$ and $2.0 \pm 0.2 \mu \mathrm{M}$ for Me501 and A375, respectively. For comparative purposes, we evaluated the cytotoxic activity of temozolomide (from 0.01 to $25 \mathrm{mM}$ ) under identical growth conditions (Panels C and D). The IC 50 values of this drug for Me501 and A375 cells were $0.61 \pm 0.06 \mathrm{mM}$ and $0.40 \pm 0.02 \mathrm{mM}$, respectively. 
cytometric analysis revealed that the intracellular equilibrium concentration was reached after 15-30 min of NBDHEX treatment in A375 cells and after 30-60 min in Me501 cells (data not shown). We then analysed the cytotoxic effect of NBDHEX on both Me501 and A375 cell lines. The dose-response profile obtained after $48 \mathrm{~h}$ of treatment with NBDHEX gave $\mathrm{IC}_{50}$ values of $1.2 \pm 0.1 \mu \mathrm{M}$ and $2.0 \pm 0.2 \mu \mathrm{M}$ for Me501 and A375, respectively (Fig. 1, panels A and B). NBDHEX was also compared to temozolomide under identical growth conditions. After $48 \mathrm{~h}$ of treatment, the $\mathrm{IC}_{50}$ values of temozolomide for Me501 and A375 cells were $0.61 \pm 0.06 \mathrm{mM}$ and $0.40 \pm 0.02 \mathrm{mM}$, respectively (Fig. 1, panels C and D). Therefore, the NBDHEX antitumour efficacy in melanoma cell lines is comparable to that observed in other tumour cell lines, ${ }^{7,12,19}$ and is over 100 times higher than that of temozolomide, indicating that NBDHEX is a potential candidate for the treatment of melanoma as well.

\subsection{NBDHEX triggers apoptosis in Me501 and A375 cells}

To determine if the NBDHEX treatment was able to trigger cell death in melanoma, we evaluated the occurrence of apoptosis by determining the degree of nuclear condensation and fragmentation (Fig. 2, panel A). Fluorescence microscopy analysis revealed that apoptosis in Me501 cells occurred within $3 \mathrm{~h}$ and continued to increase throughout the incubation period, reaching approximately $60 \%$ at $24 \mathrm{~h}$. In A375 cells, the apoptotic event was rather late compared to Me501 cells; in fact, the percentage of apoptotic cells was $22 \%$ and $38 \%$ at 24 and $48 \mathrm{~h}$, respectively (Fig. 2, panel B). Apoptosis was also confirmed by a time-dependent increase in caspase-3 activity. The proteolytic activity paralleled the time course of nuclear fragmentation in both Me501 and A375 cell lines (Fig. 2, panel C). Moreover, an early activation of caspase- 9 was observed in the Me501 cell line, while an active caspase- 9 band was observed only at $24-48 \mathrm{~h}$ in A375 cells (Fig. 2, panel D). Conversely, pro-caspase-8 was not affected by NBDHEX treatment in both cell lines as neither change in the expression level nor appearance of cleaved bands (data not shown) was observed. This is in accordance with previous evidence showing that NBDHEX triggers an intrinsic apoptotic pathway. $^{12}$

\subsection{NBDHEX causes cell-cycle arrest in A375 cells}

In A375 cells, exposure to NBDHEX caused an early cell growth inhibition (Fig. 3, panel A). The early reduction of the number of cells was not a consequence of cell death, as
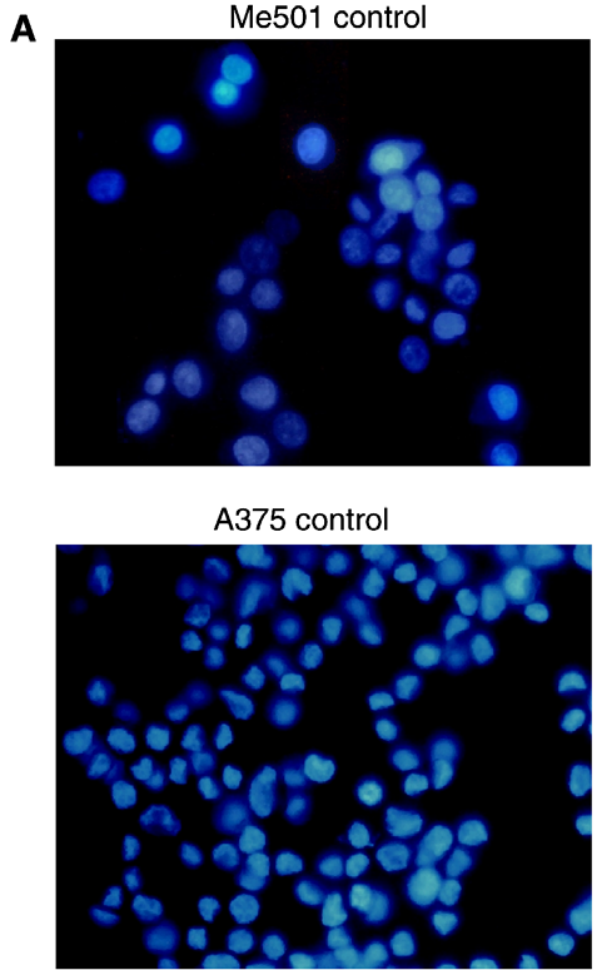
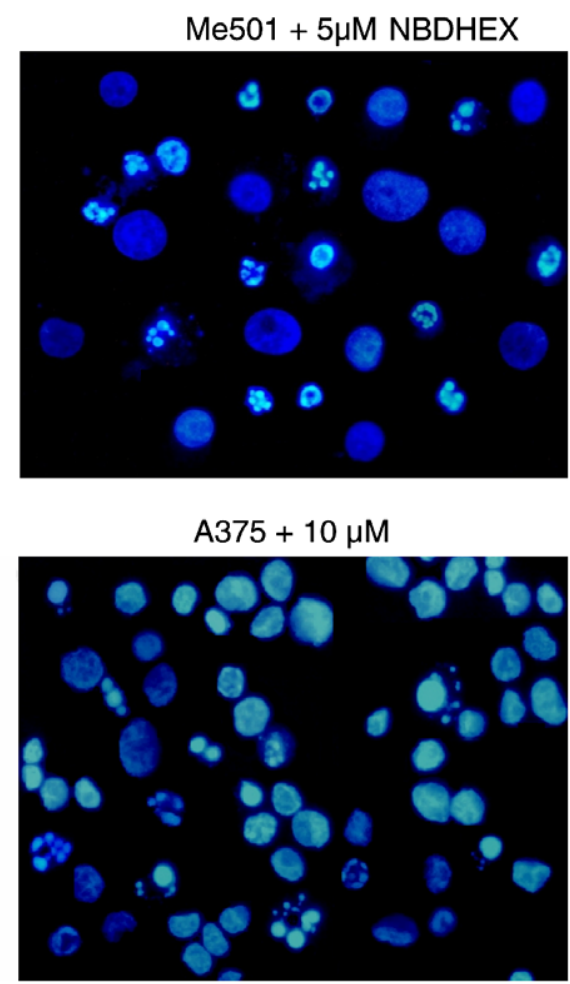

Fig. 2 - NBDHEX induces apoptosis in Me501 and A375 cell lines. Panel A, Cells were stained with Hoechst 33342 after 24 h of treatment with NBDHEX. Panel B, The time-course analysis of NBDHEX-driven apoptosis was determined by estimating the number of nuclei with typical apoptotic morphology. Panel C, The time-dependent increase in caspase-3 activity was evaluated as reported in Section 2 and expressed as percentage of the maximum value. Me501 and A375 cells treated with $5 \mu \mathrm{M}$ and $10 \mu \mathrm{M}$ NBDHEX, respectively $(\square)$ and untreated cells $(\Delta)$. Panel D, The levels of uncleaved (inactive) and cleaved (active) caspase-9 were detected at indicated time points in both Me501 and A375 cells treated with 5 and $10 \mu \mathrm{M}$ NBDHEX, respectively. $\beta$-Tubulin was used as loading control. The immunoblot shown is from one experiment representative of three that gave similar results. 

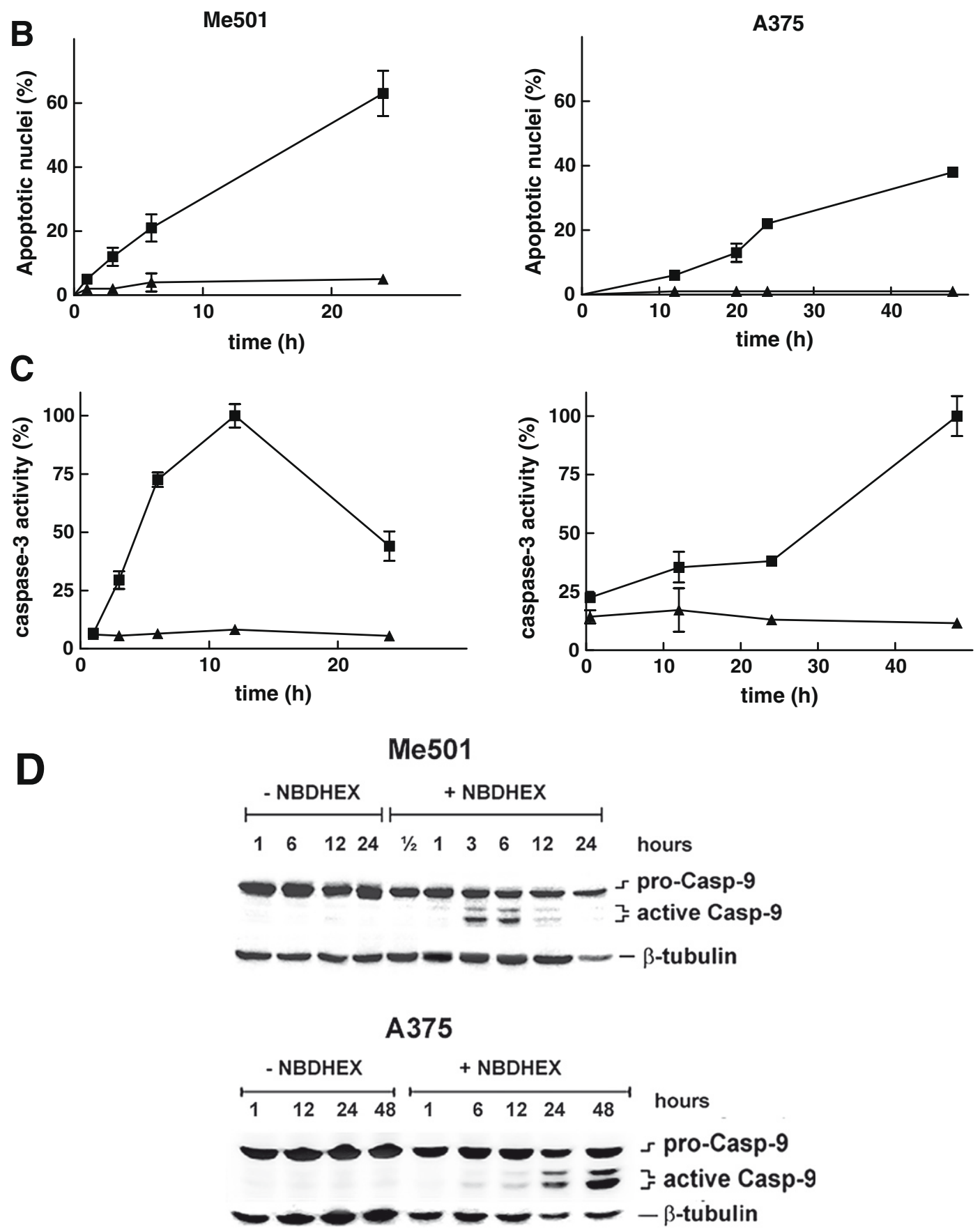

Fig. 2. (continued)

the degree of necrosis did not exceed $5 \%$ up to $12 \mathrm{~h}$ of treatment. Flow cytometric analysis showed a time-dependent accumulation of cells in the $\mathrm{G} 2 / \mathrm{M}$ phase (Fig. 3, panels $B$ and $\mathrm{C}$ ). On the other hand, flow cytometric analysis of Me501 cells showed no time-dependent accumulation in the G2/M phase (data not shown), consistent with the earlier activation of the caspases and apoptosis in this cell line.

\subsection{Effect of JNK and p38 inhibition}

The mitogen-activated protein kinases (MAPKs) JNK and p38 play a relevant role in regulating both the apoptotic event and the cell-cycle arrest. NBDHEX is able to induce the activation of these MAPKs in cancer cells from different tissues. ${ }^{7,12,13}$ Therefore, to establish the possible involvement of JNK and p38 in the signalling pathways activated by NBDHEX, we studied the effect of specific MAPK inhibitors. In the Me501 cell line, the JNK inhibitor SP600125 caused morphological changes and G2/M arrest; hence the role of JNK could not be established in this cell line. Non-toxic concentrations of SP600125 caused a drastic decrease in caspase- 3 activity in A375 cell line, suggesting the involvement of the JNK pathway in the NBDHEX-mediated apoptosis (Fig. 4, panel A). By contrast, SP600125 did not revert cell-cycle arrest (Fig. 4, 
A

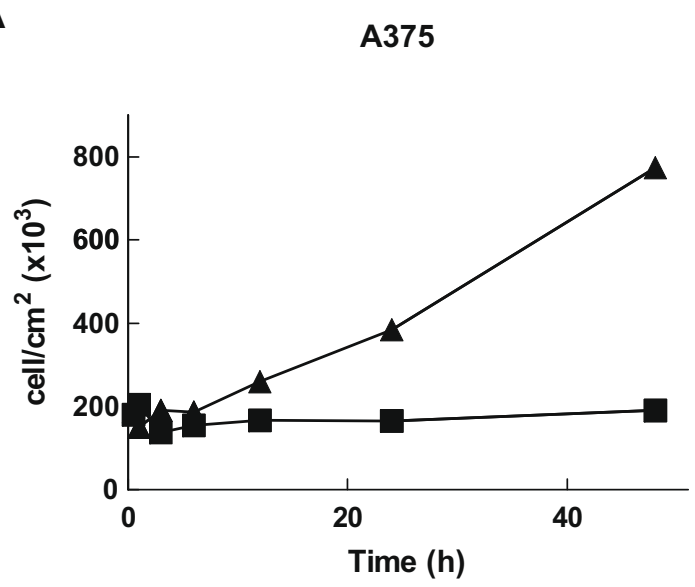

B

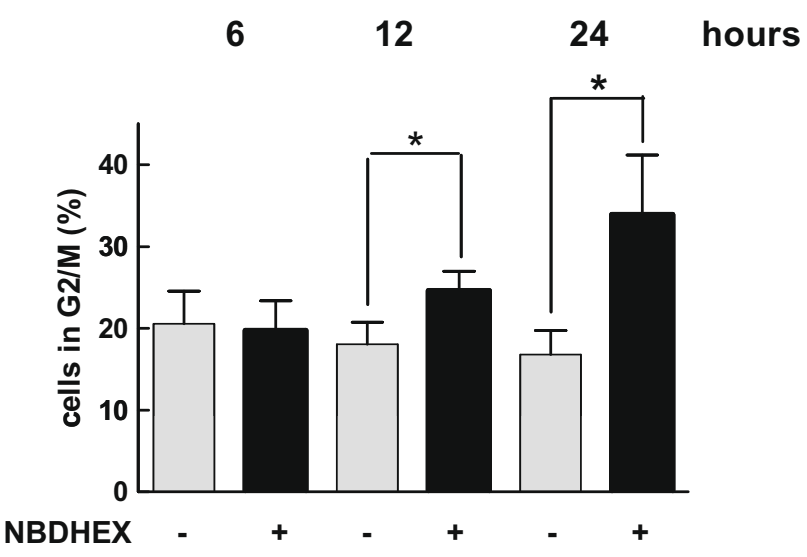

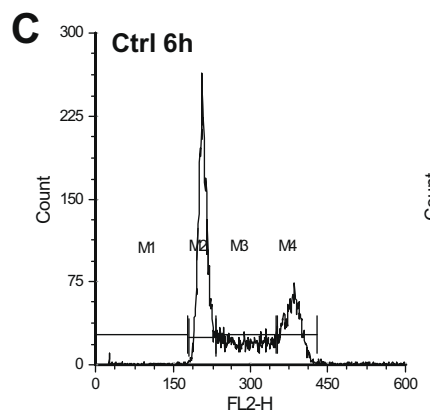
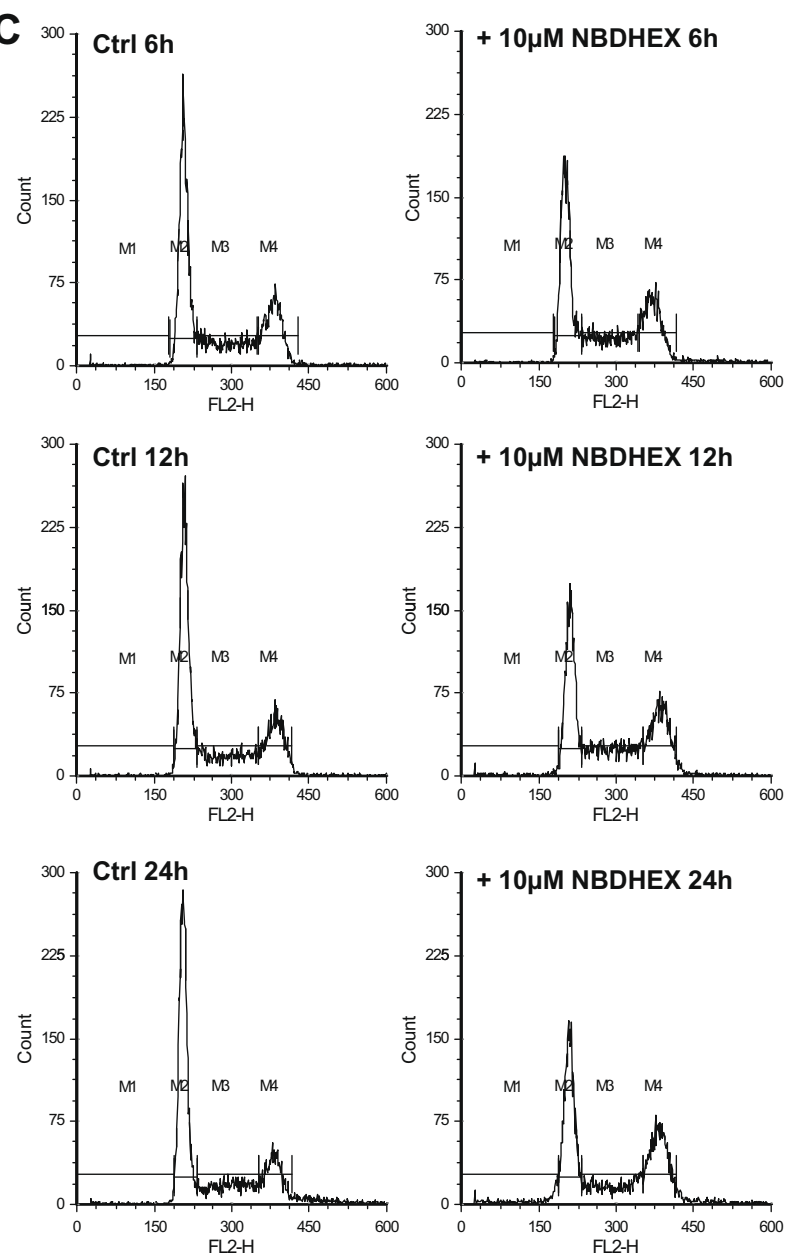

Fig. 3 - NBDHEX suppresses A375 cell proliferation and causes a cell-cycle arrest in G2/M phase. Panel A, Treatment with $10 \mu \mathrm{M}$ NBDHEX induced a sustained growth inhibition of $A 375$ cells $(\square)$, while the untreated cells ( $\Delta$ ) quadrupled their number during the same incubation time. Panel B, A375 cells were treated with $10 \mu \mathrm{M}$ NBDHEX and subjected to cell-cycle analysis after different incubation times $(6,12$ and $24 \mathrm{~h})$. The percent of cells in the G2/M phase was calculated by the ModFit LT cellcycle analysis program. Data represent the means \pm SD of four independent experiments, $\left({ }^{*}\right) P<0.05$. Panel C, Representative profiles of cell-cycle distribution in NBDHEX-treated A375 cells.

panel A). Non-toxic concentrations of the p38 inhibitor, SB203580 did not protect Me501 cells against apoptosis triggered by NBDHEX (Fig. 4, panel B). Likewise, SB203580 did not suppress caspase- 3 activation in A375 cells treated with NBDHEX but caused an increase in caspase- 3 activity. Moreover, the inhibition of $\mathrm{p} 38$ did not reverse the cell-cycle arrest in this cell line (Fig. 4, panel C). Therefore, the activation of p38 seems to be not required for either the antiproliferative or the proapoptotic effects of NBDHEX.

\subsection{Evidence of JNK and c-Jun activation in Me501 and A375 cells}

Western blot analysis of Me501 cells, treated with NBDHEX, showed a rapid and sustained increase in the phospho-active form of JNK, which remained active up to $12 \mathrm{~h}$. After $3 \mathrm{~h}, \mathrm{c}-$ Jun, a direct downstream transcription factor substrate of JNK, was also activated (Fig. 5, panel A). Conversely, NBDHEX caused in the A375 cell line an early transient phase of JNK activation, characterised by faint P-JNK bands, and a second phase, starting at approximately $12 \mathrm{~h}$, by elevated amounts of P-JNK (Fig. 5, panel B). The first P-JNK activation was concomitant with the activation of c-Jun and preceded apoptosis. The late JNK activation was in parallel with the main phase of the apoptotic event. A P-JNK band was also found in the untreated A375 cells, where it probably supports the active proliferation of these cells; in fact, JNK is known to be constitutively activated in melanoma. ${ }^{20}$ On the other hand, in NBDHEX-treated cells, JNK plays a different role, it being involved in the apoptotic cell death. In both Me501 and A375 cell lines, the time course of JNK activation correlated well with the time course of caspases activation and nuclear fragmentation, so confirming the involvement of the JNK/C-Jun pathway in the apoptosis induced by NBDHEX in these melanoma cell lines.

\subsection{Evidence of $p 21^{\text {Waf1/Cip1 }}$ activation in A375 cells}

The arrest in G2/M phase is associated with upregulation of the cyclin-dependent kinase (CDK) inhibitor p21 ${ }^{\text {Waf1/Cip1 }}$, the 
A

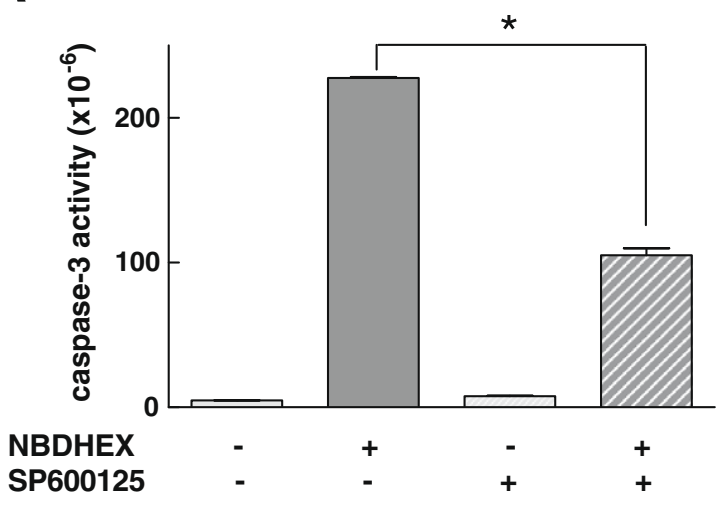

B

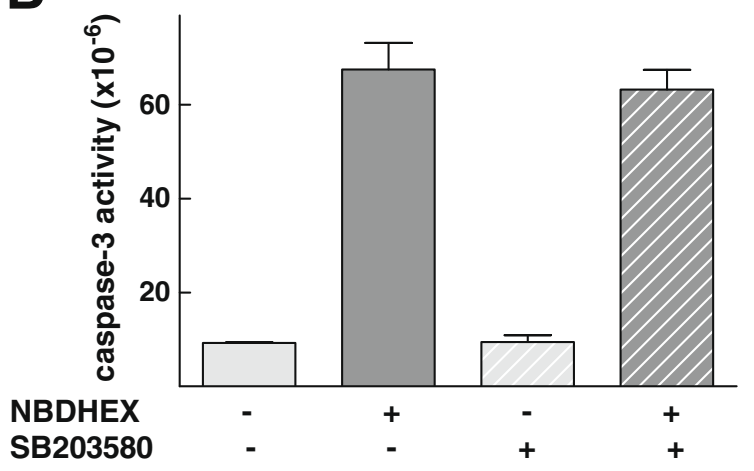

A375

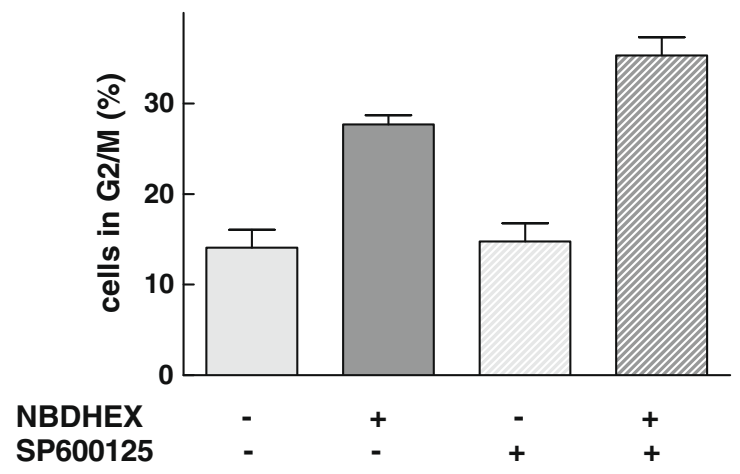

C

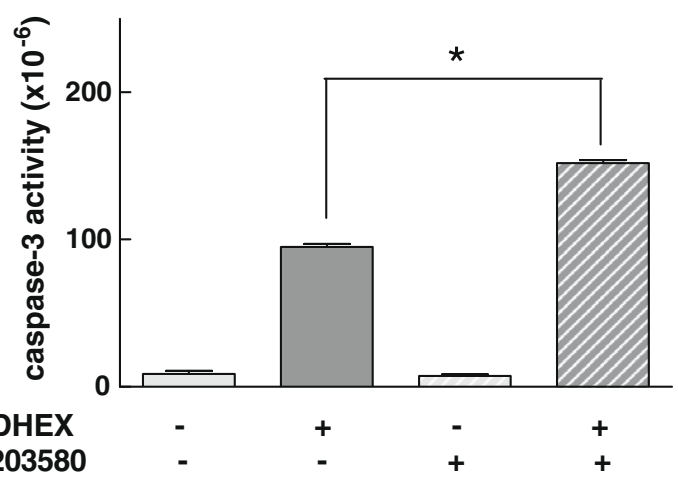

A375

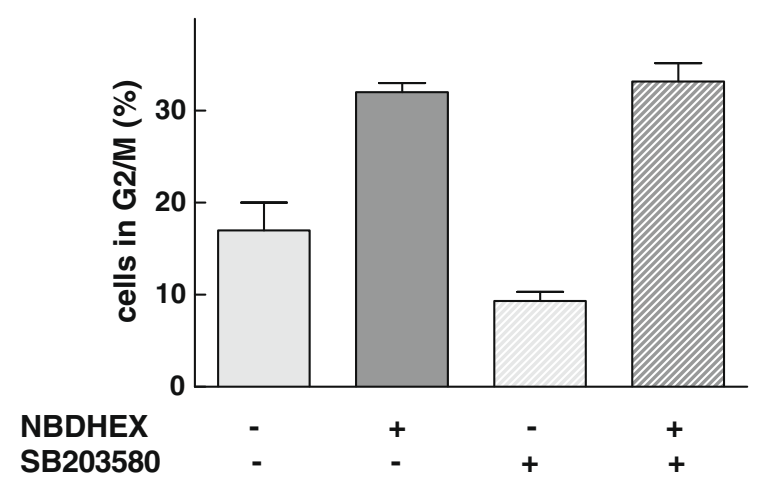

Fig. 4 - Effect of JNK and p38 inhibition. (Panel A) SP600125 (JNK inhibitor) strongly suppressed caspase-3 activation, while it did not prevent cell-cycle arrest in A375 cells. (Panel B) SB203580 (p38 inhibitor) did not prevent the caspase-3 activation in Me501 cells. Panel C, SB203580 did not revert cell-cycle arrest and apoptosis in A375 cells but caused an increase in caspase-3 activity.

most important protein involved in both G1/S and G2/M cellcycle arrest. ${ }^{21,22}$ Treatment with NBDHEX resulted in a prolonged increase in p21 levels in A375 cells; the protein concentration increased after $3 \mathrm{~h}$ of treatment with NBDHEX and remained at elevated levels for up to $48 \mathrm{~h}$ (Fig. 5, panel C). Recent studies have demonstrated that p21 can be regulated by post-translational modification mediated by MAPKs. In particular, direct phosphorylation of p21 by JNK and p38 may increase p21's abundance by increasing its stability. ${ }^{23}$ However, MAPKs inhibition experiments rule out the involvement of both JNK and p38 in cell-cycle arrest caused by NBD-
HEX. Therefore, p21, an important mediator of the cell-cycleinhibitory function of $\mathrm{p} 53,{ }^{24}$ is likely regulated by a transcriptional-dependent mechanism.

\subsection{Role of protein synthesis in A375 cells}

To clarify the requirement for protein synthesis in the events triggered by NBDHEX in A375 cells, we utilised cycloheximide, a specific protein synthesis inhibitor. Caspase-3 activation was strongly reduced in the presence of cycloheximide (Fig. 6, panel A). Therefore, the apoptotic event observed in 

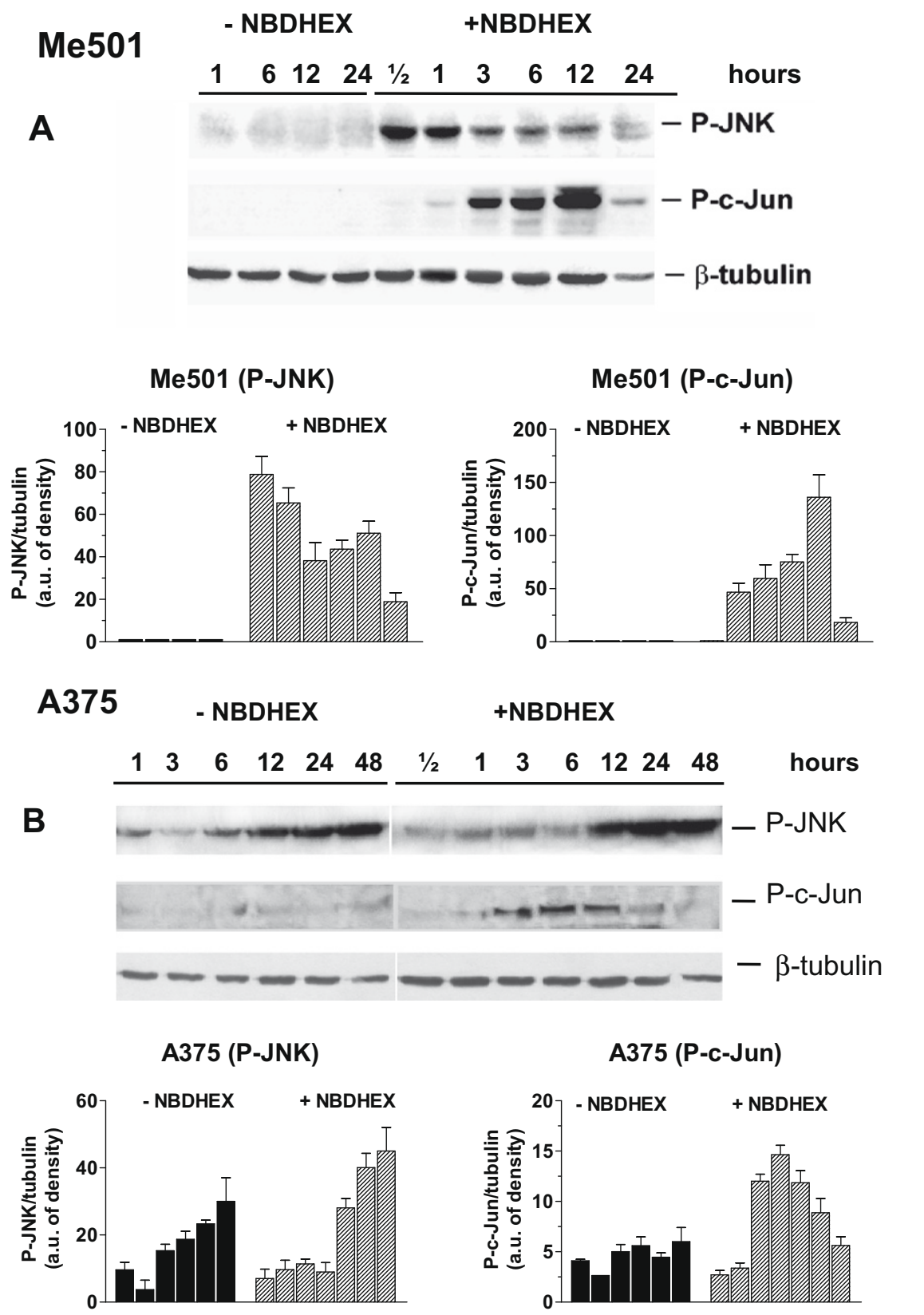

Fig. 5 - JNK and c-Jun activation. The levels of P-JNK and P-c-Jun were detected at indicated time points in both Me501 (Panel A) and A375 (Panel B) cells treated with 5 and $10 \mu \mathrm{M}$ NBDHEX, respectively. NBDHEX also induced an increase in p21 in A375 cells (Panel C); $\beta$-Tubulin was used as loading control. The immunoblot shown is from one experiment representative of three that gave similar results. The density of immunoreactive bands (reported below the immunoblot) was calculated using the software Quantity One, normalised for $\beta$-tubulin and reported as arbitrary units.

A375 cells was likely the consequence of the transcriptional activity of c-Jun. Moreover, in the presence of protein synthesis inhibitor, a lower G2/M arrest, comparable to that of the control cells, was observed (Fig. 6, panel B), confirming that cell-cycle arrest is a transcription-dependent event, most likely mediated by the transcription factor p53.

\subsection{In vivo studies}

First, we evaluated the in vivo antitumour efficacy of NBDHEX in SCID mice bearing early Me501 melanoma lesions. After
$15 \mathrm{~d}$ of daily treatment, a statistically significant tumour inhibition (approximately 70\%) was observed (Fig. 7, panel A). At sacrifice, melanoma nodules of mice treated and untreated with NBDHEX $(8 \mathrm{mg} / \mathrm{kg})$ were excised and biomarkers of proliferation, apoptosis and angiogenesis were determined. The proliferation status of tumours was measured by the mitotic index, which has been demonstrated to be a strong predictor of outcome for several human cancers. Tumours treated with NBDHEX showed a more than $50 \%$ decrease in the mitotic index (Fig. 7, panel C). The antiproliferative effect of NBDHEX was also confirmed by the reduced expression of Ki-67 and 


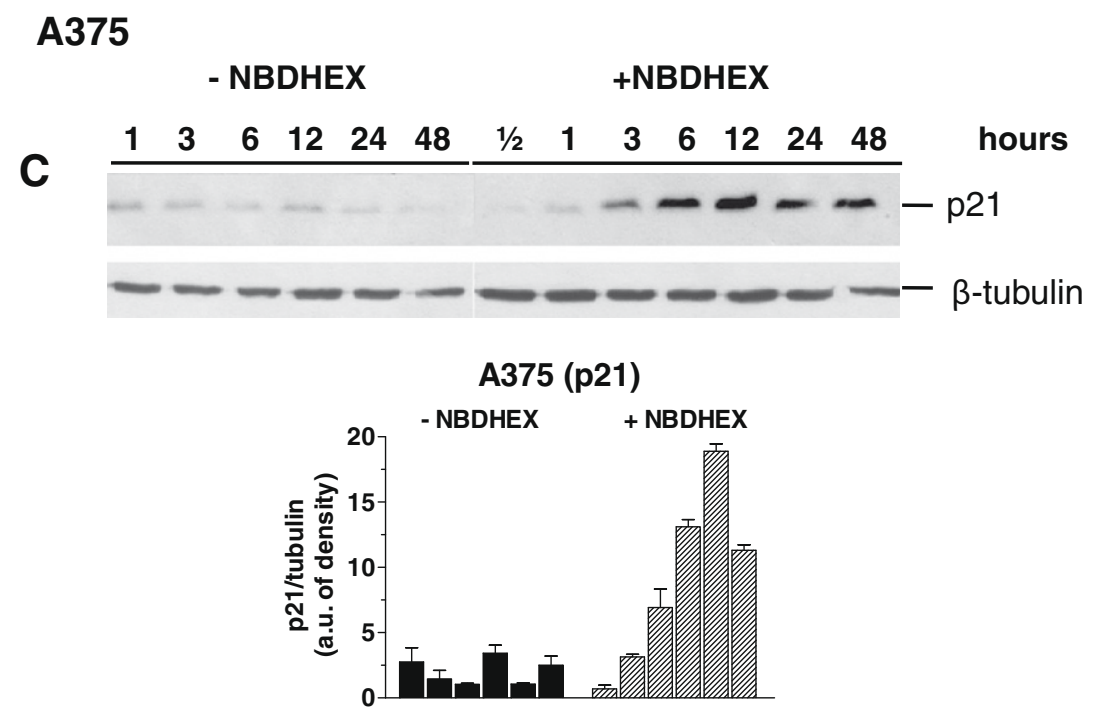

Fig. 5 (continued)

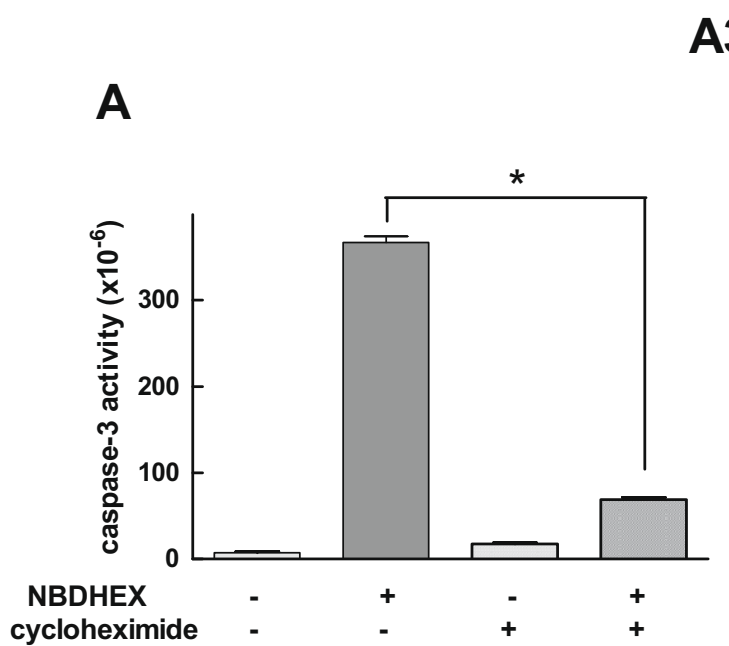

A375

Fig. 6 - Protein synthesis is required for NBDHEX effects in A375 cells. (Panel A) After $24 \mathrm{~h}$ of treatment with cycloheximide and NBDHEX, caspase-3 activity was strongly reduced. (Panel B) Likewise, in the presence of cycloheximide, a lower G2/M arrest, comparable to that of the control cells, was observed.

cyclin D1, both of which are cellular markers for proliferation $^{25}$ (Fig. 7, panels D and E, respectively). Apoptosis was observed through the significant increase of caspase-3 positive cells in NBDHEX-treated tumour xenografts (Fig. 7, panel F). An example of a tumour xenograft from a control, presenting a high number of mitotic figures and a diffuse and intense nuclear positivity for Ki-67 and cyclin D1, is shown in Fig. 7 (panels G-J). In parallel, an example of a tumour xenograft from a treated animal is reported, presenting nuclear condensation and fragmentation of apoptotic cells and a low number of cells expressing a nuclear positivity for Ki-67 and cyclin D1 (panels K-N). Moreover, the NBDHEX-treated tumour xenograft shows a diffuse positive anticaspase- 3 stain, while scarce positivity is observed in the untreated tumour xenograft and in the non-malignant tissue (Fig. 7, panels O-Q). Finally, haematoxylin and eosin slides do not reveal any difference in neoangiogenesis between treated and untreated tumour xenografts (data not shown). The efficacy of NBDHEX was then tested in advanced A375 xenografts. In this model, NBDHEX induced a significant decrease of tumour weight (approximately 63\%) after $10 \mathrm{~d}$ of daily treatment (Fig. 7, panel B), thereby confirming previous results. In all experiments, the compound was well tolerated, with no body weight reduction. Moreover, autopsy findings did not reveal any significant microscopic organ (heart, lung, liver, kidney, spleen or intestine) lesion.

\section{Discussion}

We have previously shown that NBDHEX induces apoptosis in a variety of human cancer cell lines, including leukaemia, small cell lung cancer and osteosarcoma. ${ }^{12-14,19}$ In this study 
A

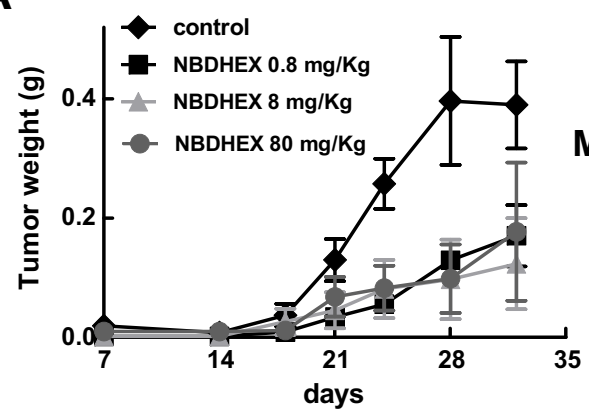

B

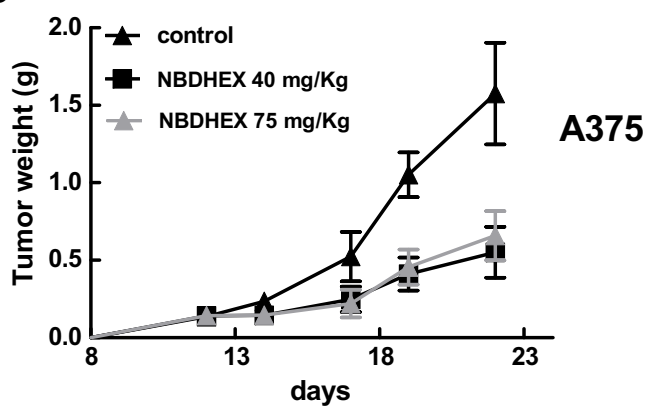

Me501
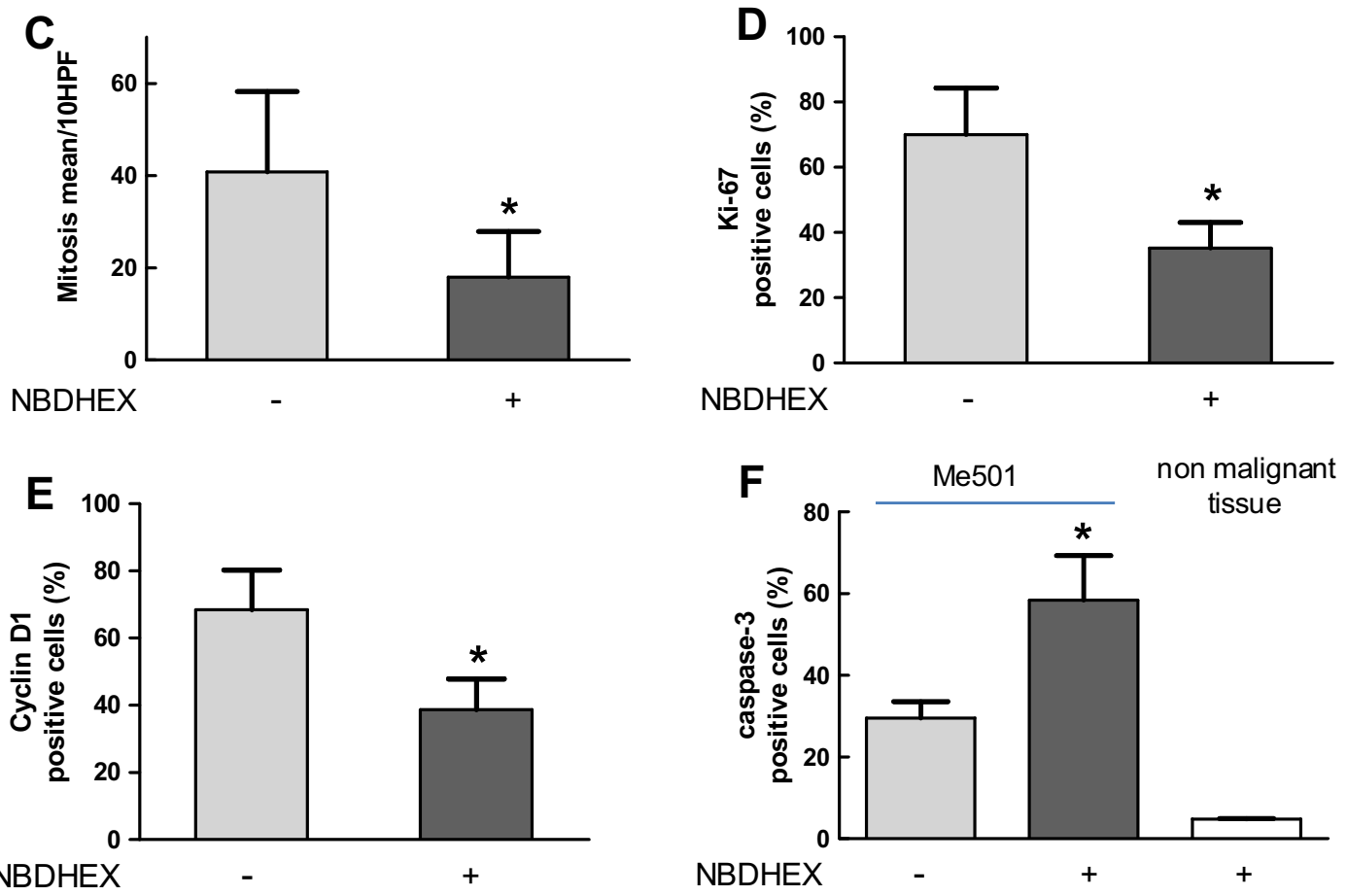

Fig. 7 - In vivo antitumour efficacy of NBDHEX. (Panel A) Antitumour efficacy of NBDHEX evaluated in Me501 melanoma xenograft-bearing SCID mice. Symbols represent the means \pm SD of tumour weight determined in eight mice for each group. After $15 \mathrm{~d}$ of daily treatment, a statistically significant tumour inhibition was observed (TI of approximately $70 \%, \mathrm{P}<0.05$ using Student's t-test). (Panel B) Antitumour efficacy of NBDHEX evaluated in A375 melanoma xenograft-bearing nude mice. Symbols represent the means \pm SD of eight mice. After $10 \mathrm{~d}$ of daily treatment, a decrease of tumour weight of approximately $63 \%$ was detected. Differences between treated and control groups were statistically significant starting from day 17 onward $(P<0.01$ using Student's t-test). (Panel C) At sacrifice $(2 \mathrm{~h}$ after final treatment), a decrease of more than $50 \%$ in the mitotic index was observed in Me501 tumours treated with NBDHEX $(8 \mathrm{mg} / \mathrm{Kg})$ compared to untreated tumours. (Panels D and E) The NBDHEX treatment also caused a significant reduction in expression of Ki-67 (D) and cyclin D1 (E), both of which are cellular markers for proliferation. (Panel F) Apoptosis in vivo was confirmed by the increase in caspase-3 expression in tumours treated with NBDHEX. (Panels G-J) Tumour xenograft from control. Panels G (magnification 20 $\times$ ) and H (magnification 60 $\times$ ) show the H\&E stain, note the high number of mitotic figures (arrows); panels I (magnification 20 $\times$ ) and J (magnification 20 $\times$ ) show, respectively, the Ki-67 and cyclin D1 stain with a diffuse and intense nuclear positivity. (Panels K-N) Tumour xenograft from treated animals. Panels K (magnification 20 $\times$ ) and L (magnification 60×) show the H\&E stain, note the nuclear condensation and fragmentation of apoptotic cells (arrows); Panels M (magnification 20 $\times$ ) and N (magnification 20x) show, respectively, the Ki-67 and cyclin D1 stain with a low number of cells expressing nuclear positivity. (Panels $O$ and $P$ ) Anticaspase-3 stain of tumour xenograft from control $(0)$ and treated animals $(P)$. The untreated tumour xenograft show sparse positivity, while the treated tumour shows a diffuse positive stain (magnification 20×). (Panel Q) Caspase-3 stain of lung tissue in an NBDHEX treated animal (magnification 20×). Scanty and faint positivity was observed mainly in bronchial epithelial (arrow). 

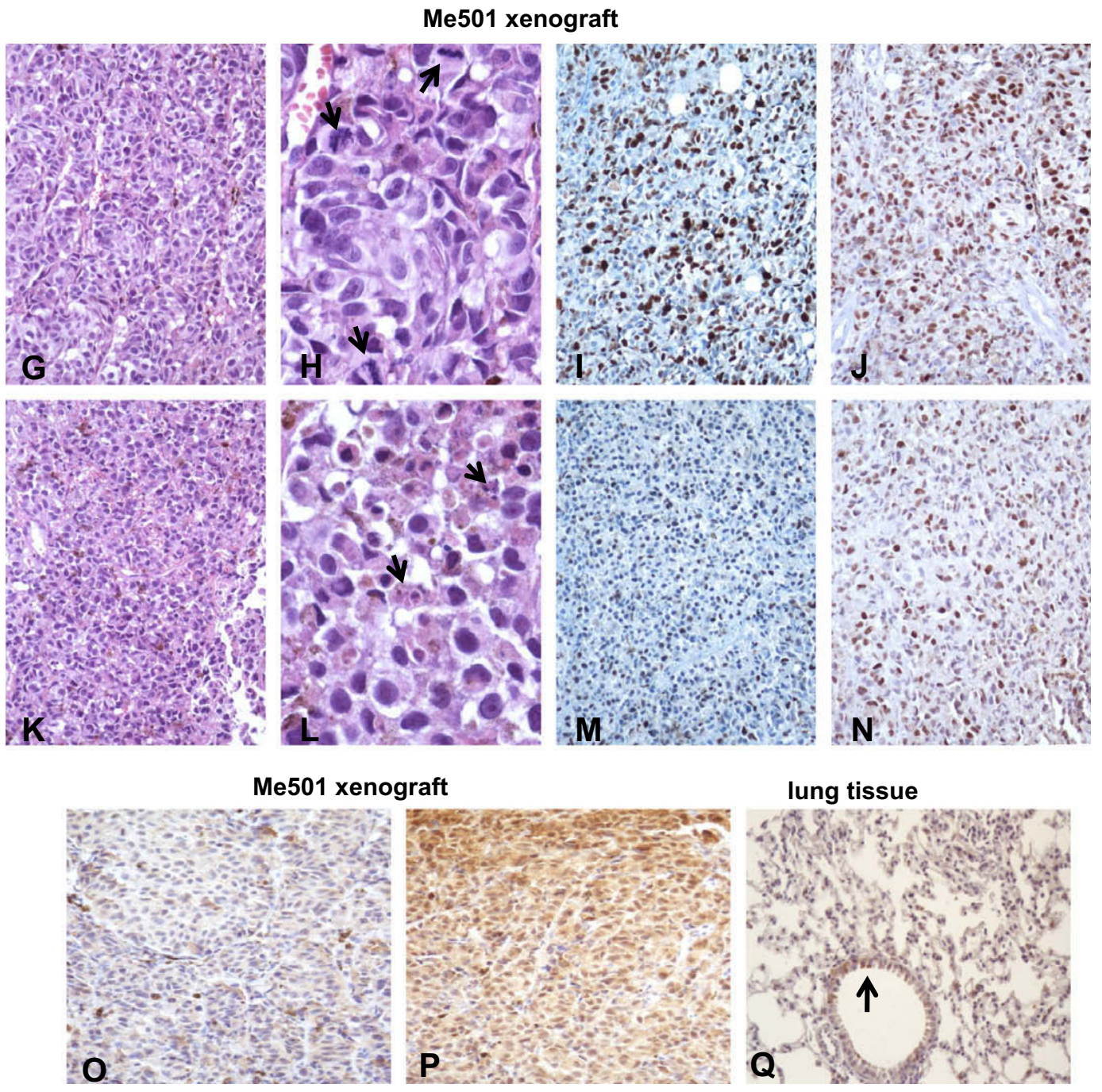

Fig. 7 (continued)

we show for the first time that NBDHEX is able to inhibit melanoma growth in vivo. Efficacy studies, performed on human Me501 and A375 melanoma xenografts, resulted in significant tumour growth inhibition (approximately 70\%). The antiproliferative effect of NBDHEX in vivo was confirmed by the decrease in the mitotic index and the reduced expression of the proliferative factors cyclin D1 and Ki-67. Furthermore, induction of apoptosis in vivo was confirmed by measuring an increase in the caspase-3 expression. Conversely, the drug does not seem to affect the degree of tumour vascularisation. NBDHEX was well tolerated at all utilised doses and this confirms previous acute toxicity experiments in mice, showing low toxicity of NBDHEX up to a dose of $125 \mathrm{mg} / \mathrm{kg}$. ${ }^{7}$ Melanoma is one of the most common as well as the most virulent forms of cancer, characterised by high chemoresistance and poor prognosis. ${ }^{26,27}$ Chemoresistance in melanoma is mainly due to improper functioning of apoptosis that is manifested in down-regulation of proteins involved in apoptosis such as Apaf-1, or high expression of anti-apoptotic proteins such as Bcl-2. ${ }^{28,29}$ As a consequence, many chemotherapeutic agents cause cell-cycle arrest but not apoptosis and this al- lows the tumour cells to overcome chemotherapy. Our data shows that NBDHEX has an antitumour efficacy in vitro over 100 times higher than that of temozolomide, which represents a new promising agent for the treatment of metastatic melanoma. In particular, NBDHEX induced an early apoptotic event in human melanoma Me501 cells, which reached about $60 \%$ after $24 \mathrm{~h}$ of treatment. Moreover, treatment with NBDHEX caused a rapid and sustained phosphorylation of JNK and c-Jun, a direct downstream transcription factor activated by JNK. These data confirm the mechanism already described in CCRF-CEM and K562 leukaemias and on small cell lung cancer. $^{7,13}$ The mechanism of cell death was also evaluated on A375 cells, which has been shown to express different proteins conferring drug resistance in melanoma tumours., ${ }^{9,15}$ Interestingly, NBDHEX treatment of A375 cells first resulted in cell-cycle arrest, but then, within $48 \mathrm{~h}$, caused a remarkable increase in apoptosis. Also in A375 cell line the JNK activity was required for the NBDHEX-triggered apoptosis confirming that the JNK/c-Jun pathway is an important therapeutic target for this tumour. These results are consistent with previous evidences showing that JNK activation is a critical event for 
the antitumour activity of several drugs in melanoma. In particular, apoptosis induced in melanoma cells by docetaxel and vincristine, among the most active drugs in cancer treatment, is strictly dependent on the activation of $\mathrm{JNK}^{30,31}$ In addition, our findings indicate that activation of JNK/c-Jun pathway, through a selective GSTP1-1 targeting, could prove a promising new strategy for treating melanoma.

\section{Conflict of interest statement}

None declared.

\section{Acknowledgement}

We thank Albino Cesolini for the excellent work on animal tumour models.

\section{R E F E R E N C E S}

1. Pipeline insight: cancer overview - gastrointestinal, skin, sarcomas. Datamonitor Pharmaceutical Report; 2008. p. 11823.

2. Helmbach H, Rossmann E, Kern MA, Schadendorf D. Drugresistance in human melanoma. Int J Cancer 2001;93(5):617-22.

3. Eton O, Legha SS, Bedikian AY, et al. Sequential biochemotherapy versus chemotherapy for metastatic melanoma: results from a phase III randomized trial. J Clin Oncol 2002;20(8):2045-52.

4. Middleton MR, Lorigan $\mathrm{P}$, Owen J, et al. A randomised phase III study comparing dacarbazine, BCNU, cisplatin and tamoxifen with dacarbazine and interferon in advanced melanoma. Br J Cancer 2000;82:1158-62.

5. Quirt I, Verma S, Petrella T, Bak K, Charette M. Temozolomide for the treatment of metastatic melanoma: a systematic review. The Oncologist 2007;12:1114-23.

6. Lowe SW, Lin AW. Apoptosis in cancer. Carcinogenesis 2000;21:485-95.

7. Turella P, Cerella C, Filomeni G, et al. Proapoptotic activity of new glutathione S-transferase inhibitors. Cancer Res 2005;65(9):3751-61.

8. Townsend DM, Tew KD. The role of glutathione-S transferase in anti-cancer drug resistance. Oncogene 2003;22:7369-75.

9. Depeille P, Cuq P, Passagne I, Evrard A, Vian L. Combined effects of GSTP1 and MRP1 in melanoma drug resistance. $\mathrm{Br} J$ Cancer 2005;93(2):216-23.

10. Awasthi YC, Sharma R, Yadav S, Dwivedi S, Sharma A, Awasthi S. The non-ABC drug transporter RLIP76 (RALBP-1) plays a major role in the mechanisms of drug resistance. Curr Drug Metab 2007;8(4):315-23.

11. Colone M, Calcabrini A, Toccacieli L, et al. The multidrug transporter P-glycoprotein: a mediator of melanoma invasion? J Invest Dermatol 2008;128(4):957-71.

12. Turella P, Filomeni G, Dupuis ML, et al. A strong glutathione S-transferase inhibitor overcomes the P-glycoproteinmediated resistance in tumor cells. 6-(7-Nitro- 2, 1, 3benzoxadiazol-4-ylthio) hexanol (NBDHEX) triggers a caspase-dependent apoptosis in MDR1-expressing leukemia cells. J Biol Chem 2006;281:23725-32.

13. Filomeni G, Turella P, Dupuis ML, et al. 6-(7-Nitro-2, 1, 3benzoxadiazol-4-ylthio)hexanol, a specific glutathione S- transferase inhibitor, overcomes the multidrug resistance (MDR)-associated protein 1-mediated MDR in small cell lung cancer. Mol Cancer Ther 2008;7(2):371-9.

14. Ascione A, Cianfriglia M, Dupuis ML, et al. The glutathione Stransferase 6-(7-nitro-2, 1, 3-benzoxadiazol-4-ylthio)hexanol overcomes the MDR1-P-glycoprotein and MRP1-mediated multidrug resistance in acute myeloid leukemia cells. Cancer Chemother Pharmacol 2009;64(2):419-24.

15. Chawla-Sarkar M, Bae SI, Reu FJ, Jacobs BS, Lindner DJ, Borden EC. Downregulation of Bcl-2, FLIP or IAPs (XIAP and survivin) by siRNAs sensitizes resistant melanoma cells to Apo2L/ TRAIL-induced apoptosis. Cell Death Differ 2004;11(8):915-23.

16. Ricci G, De Maria F, Antonini G, et al. 7-Nitro-2,1,3benzoxadiazole derivatives, a new class of suicide inhibitors for glutathione S-transferases. Mechanism of action of potential anticancer drugs. J Biol Chem 2005;280(28):26397-405.

17. Lugini L, Lozupone F, Matarrese P, et al. Potent phagocytic activity discriminates metastatic and primary human malignant melanomas: a key role of Ezrin. Lab Invest 2003;83(11):1555-67.

18. Skehan P, Storeng R, Scudiero D, et al. New colorimetric cytotoxicity assay for anticancer-drug screening. J Natl Cancer Inst 1990;82:1107-12.

19. Pasello M, Michelacci F, Scionti I, et al. Overcoming glutathione S-transferase P1-related cisplatin resistance in osteosarcoma. Cancer Res 2008;68:6661-8.

20. Lopez-Bergami P, Huang C, Goydos JS, et al. Rewired ERK-JNK Signaling Pathways in Melanoma. Cancer Cell 2007;11:447-60.

21. Wong SH, Shih RS, Schoene NW, Lei KY. Zinc-induced G2/M blockage is p53 and p21 dependent in normal human bronchial epithelial cells. Am J Physiol Cell Physiol 2008;294(6):C1342-9.

22. Selvendiran $\mathrm{K}$, Tong L, Vishwanath S, et al. EF24 induces G2/ $\mathrm{M}$ arrest and apoptosis in cisplatin-resistant human ovarian cancer cells by increasing PTEN expression. J Biol Chem 2007;282(39):28609-18.

23. Kim GY, Mercer SE, Ewton DZ, Yan Z, Jin K, Friedman E. The stress-activated protein kinases p38 alpha and JNK1 stabilize p21(CIP1) by phosphorylation. J Biol Chem 2002;277(33):29792-802.

24. Bunz F, Dutriaux A, Lengauer C, et al. Requirement for p53 and p21 to sustain G2 arrest after DNA damage. Science 1998;282(5393):1497-501.

25. Whitfield ML, George LK, Grant GD, Perou CM. Common markers of proliferation. Nat Rev Cancer 2006;6(2):99-106.

26. Rozenblat S, Grossman S, Bergman M, Gottlieb H, Cohen Y, Dovrat S. Induction of G2/M arrest and apoptosis by sesquiterpene lactones in human melanoma cell lines. Biochem Pharmacol 2008;75(2):369-82.

27. Eberle J, Kurbanov BM, Hossini AM, Trefzer U, Fecker LF. Overcoming apoptosis deficiency of melanoma-hope for new therapeutic approaches. Drug Resist Updat 2007;10(6):218-34.

28. Soengas MS, Capodieci P, Polsky D, et al. Inactivation of the apoptosis effector Apaf-1 in malignant melanoma. Nature 2001;409(6817):207-11.

29. Leiter U, Schmid RM, Kaskel P, Peter RU, Krähn G. Antiapoptotic bcl-2 and bcl-xL in advanced malignant melanoma. Arch Dermatol Res 2000;292(5):225-32.

30. Mhaidat NM, Zhang XD, Jiang CC, Hersey P. Docetaxelinduced apoptosis of human melanoma is mediated by activation of c-Jun NH2-terminal kinase and inhibited by the mitogen-activated protein kinase extracellular signalregulated kinase $1 / 2$ pathway. Clin Cancer Res 2007;13(4):1308-14.

31. Zhu BK, Wang $P$, Zhang XD, et al. Activation of Jun N-terminal kinase is a mediator of vincristine-induced apoptosis of melanoma cells. Anticancer Drugs 2008;19(2):189-200. 